\title{
Comentário VII
}

\section{Ronaldo Vainfas}

Universidade Federal Fluminense

O texto de Mary Del Priore traça um panorama geral do que seria uma história do corpo, suas linhagens, os temas que a esboçaram e aqueles que hoje fariam do corpo um objeto evidente da pesquisa histórica. "Tirando a roupa" é o subtítulo que introduz o assunto; "deitando na cama" é o que dá conta do esboço de uma história do corpo; "o corpo - modo de usar", descortina a historiografia mais recente que, diversificando as abordagens, fez do corpo um objeto e ampliou, de certo modo, os horizontes de investigação histórica. E "curvas e linhas metodológicas" é o ítem conclusivo, indicando as possibilidades e os dilemas dos historiadores dedicados ao corpo.

Há, decerto, inúmeras questões levantadas neste ensaio, texto de notável erudição bibliográfica, que mereceriam comentário. Vou me ater, porém, a alguns aspectos que possam funcionar talvez como contraponto e, portanto, como incentivo ao diálogo proposto por esta seção.

Antes de tudo, não parece clara a questão proposta pela autora acerca do "por quê de uma História do corpo", para usar suas palavras, ou de quando surgiv essa história e de como se propôs o corpo como objeto dos historiadores, se é que tais questões são válidas e respondiveis. Mary Del Priore parece desconfiar, com boas razões, da possibilidade de respondê-las com um mínimo de precisão, mas valoriza, em todo caso, a aproximação entre História e Antropologia e a "contribuição" da Nouvelle Histoire na configuração deste objeto, sobretudo nos estudos ligados às mentalidades, após a década de 1970. Esboça, por outro lado, uma espécie de cronologia, um tanto vaga, é verdade, mas que identifica 
uma "pré-história" do corpo alinhavada na altura dos anos 70; uma história do corpo muito ligada aos estudos sobre a sexualidade na segunda metade dos anos 70 e ao longo dos 80; uma história do corpo diversificada em termos de olhares e temas nos últimos 10 ou 15 anos.

No tocante ao "por quê de uma história do corpo", e sem ter aqui a menor pretensão de responder à pergunta, Del Priore tem alguma razão em sugerir que a possibilidade de uma história do corpo foi aberta aos historiadores pelos etnólogos e antropólogos. Bastaria citar, limitando-me a um só exemplo da Antropologia Social britânica (funcionalista), The sexual life of savages livro de Malinowski sobre os trobriandeses, datado de 1929, entre muitos outros que, estudando o parentesco de determinados grupos culturais em trabalhos de campo, debruçaram-se sobre o corpo, seus usos sexuais e os tabus a ele ligados.

Mas se não há dúvida de que a pesquisa antropológica iluminou o corpo para a história, não são absolutamente claros, por outro lado, os caminhos através dos quais isto se deu, nem "qual antropologia" foi mais fecunda para o trabalho historiográfico. Mary Del Priore valoriza a contribuição antropológica tanto para o esboço de uma "pré-história do corpo", como para a afirmação deste campo de estudos após a década de 1980. No entanto, ocorre-me que a aproximação entre história e antropologia - e já Lucien Febvre a valorizava nas primeiras décadas dos Annales -, não levou os historiadores franceses a fazer do corpo uma preocupação relevante de seus trabalhos. Esta aproximação parece ter inspirado, mais nitidamente, o que chamaria aqui de "pré-história das mentalidades", a exemplo de Les rois thaumaturges, de Marc Bloch (1924), ou Le problème de l'incroyance, de Febvre (1942). Nos dois casos - e os considero emblemáticos por serem obras de "pais fundadores" da Nouvelle Histoire - 0 mental tem a ver, fundamentalmente, com crenças, religiosidades, modos de pensar.

Se a contribuição dos antropólogos (Frazer, Lévy-Bruhll) foi importante na aurora dos Annales, ela não parece ter estimulado nenhum interesse pelo corpo. Creio que, nesta altura dos acontecimentos, o corpo não entrou em cena sequer como coadjuvante - e apesar de o livro de Bloch dedicar-se ao estudo da crença no poder do toque real para a cura das escrófulas. Neste sentido, talvez tenha sido a Antropologia Estrutural dos anos 50 e 60 a mais fecunda, e menos pelos objetos investigados do que pelo modo como foi lida e filtrada pelos historiadores das mentalidades na segunda metade da década de 70, sobretudo quanto à fragmentação do todo social presente em vários estudos da "era pós-Braudel". Seja como for, Mary Del Priore sugere mesmo que foi neste contexto que uma história do corpo começou a desabrochar.

Por outro lado, se parecem algo nebulosos os influxos da Antropologia no surgimento de uma história do corpo, não resta dúvida de que Del Priore tem razão ao sugerir que tal história nasceu fora da história. O mesmo afirma André Burguiere, de outro modo, no verbete corpo de seu Dicionário das ciências históricas: "os historiadores não chegaram, por sua própria iniciativa, à história do corpo", mas foram buscá-la na história das doenças feita pelos médicos, na história da tortura feita pelos advogados, na história do corpo feminino feita pelas mulheres, após Simone de Beauvoir e, uma vez mais, nos estudos etnológicos 11993: 175).

Dois autores, no entanto, me parecem ter desempenhado um papel 
fundamental na valorização do corpo, se não como objeto central, certamente como matéria de estudo dos historiadores. Refiro-me a Norbert Elias e a Michel Foucault, um sociólogo, outro filósofo (se posso chamá-los assim), cujas reflexões e ensaios me parecem ter sido capitais para a pesquisa do corpo feita pelos historiadores a partir dos anos 70 .

É inegável o impacto da obra foucaultiana nos estudos franceses que fizeram do corpo assunto de pesquisa le não entendi porque Del Priore não the deu destaque em seu ensaio), apesar de que Foucault custou, como se sabe, a ser reconhecido pelos historiadores como autor relevante - praticamente ignorado pela historiografia "oficial" francesa até a década de 70. Mas há de ter exercido uma poderosa "influência silenciosa", a julgar pelos vários temas que notabilizaram a "história das mentalidades" e, sobretudo, pelo questionamento que fez da própria história, ao sugerir a "autonomia do discurso" e sua conexão com as tecnologias de poder, considerado, este último, como coextensivo ao social e nele pulverizado. E não seria ocioso lembrar, seguindo os passos de Patricia $O^{\prime} B$ rien, que não obstante "ignorado" nos anos 1960, Foucault aparece como um dos "historiadores" mais citados, na mesma década, segundo as compilações de Megill, no índice de citações das artes e humanidades, figurando ao lado de "historiadores" como Panofsky, Gombrich, Thomas Kuhn e Mircea Eliade... (O'Brien 1992: 37-38).

Muito já se escreveu e discutiu sobre a importância de Foucault na Nova História francesa (e também a praticada na Inglaterra e nos Estados Unidos), de modo que não vejo razão para retomar o que outros fizeram melhor do que se faria aqui. Mas vale frisar que Foucault talvez tenha sido decisivo não apenas para o "surto" da historiografia sobre a sexualidade nos anos 70 e 80, como para os estudos sobre o poder - o exercício do poder, suas estratégias, a "disciplinarização" dos corpos.

No campo da história da sexualidade, que por algum tempo foi comumente associada à "história do corpo", não cabe dúvida sobre o impacto do volume publicado por Foucault em 1967 (La volonté du savoir); o primeiro de sua História da sexualidade. É verdade que a maior parte dos historiadores dedicados à história da sexualidade lançou-se à problemática muito diversa da sugerida por Foucault, vasculhando, como bem lembra Mary Del Priore, os caminhos da repressão sexual no Ocidente e das lécnicas empenhadas em introjetar a "recusa do prazer". É também verdade que, nesta mesma linha da "repressão sexual", outros escreveram obras fundamentais no campo das mentalidades - e antes de Foucault -, a exemplo de Jean-Louis Flandrin, historiador que Del Priore merecidamente destaca.

Mas penso ter sido o primeiro volume da História da sexualidade de Foucault uma referência fundamental dos estudos neste campo, durante os anos 70 e parte dos 80 (sem falar nos outros dois de 1984), nem tanto pelos métodos ou pelas suas interpretações de conjunto, mas no tocante à colocação do problema e à entronização do corpo como matéria de investigação histórica. Diria o mesmo de Vigiar e Punir, obra do Foucault mais "reconhecido" pelos historiadores (1975), cujas preocupações com a tortura, o castigo exemplar e a prisão - temas que, quando menos, "passam" pelo tema do corpo - têm irrigado diversos estudos, incluindo alguns recentíssimos citados por Del Priore em seu ensaio.

Quanto a Norbert Elias, é Mary Del Priore quem Ihe atribui a devida 
importância, citando O processo civilizador, livro de 1939 que postulou, nas palavras da autora, "uma hipótese geral sobre a evolução dos comportamentos, e em particular, das relações com o corpo na civilização européia". Uma "história dos costumes" - subtítulo escolhido pelo próprio Elias -, cuja contribuição mais original para uma história do corpo talvez resida na magnífica análise dos manuais de civilidade produzidos no Antigo Regime, de como os receituários sobre como e onde comer, dormir, expor-se, extravazar necessidades fisiológicas, etc. preconizavam um sistema de self-control - verdadeiro processo de individuação ligado à formação do Estado moderno e da própria "civilização ocidental".

Norbert Elias, à semelhança de Foucault, teve que esperar o fim da década de 60 para ser difundido entre os historiadores das "mentalidades" - 0 que talvez se deva à sua inserção na tradição intelectual alemã -, mas é inegável que inspirou inúmeros trabalhos e autores citados por Del Priore em seu ensaio: a Histoire de la pudeur (1986), de Jean-Claude Bologne, por exemplo, e vários estudos inclusos no citado Le corps dans la societé espagnole des XVle et XVIle siècles (1990).

Não deixa de ser intrigante - se é que uso aqui o adjetivo correto -, observar quão díspares são Foucault e Elias em vários aspectos, não obstante as convergências, inclusive a que mais interessa à nossa discussão: o problema da "disciplinarização" do corpo como tema de investigação histórica. Escreveu Elias nos anos 1930, acuado pelo nazismo, enquanto Foucault o fez em meio à "revolução dos costumes" dos anos 60. Preocupava-se Elias com o macro-histórico (o Estado, a gênese da civilização ocidental), ao passo que Foucault empenhava-se em desfazer a "crença científica" em uma história totalizante, estimulando com isso uma "história em migalhas". O corpo, de todo modo, foi por ambos iluminado como campo privilegiado de pesquisa para os historiadores - e deixo para Mary Del Priore comentar o assunto, se for, é claro, do seu interesse.

Mas há outro aspecto do ensaio em questão que não gostaria de deixar sem comentário. Refiro-me à idéia de que, segundo Del Priore, os estudos sobre "a normatização dos usos do corpo e da sexualidade" pertenceriam ainda, de certo modo, a uma "pré-história" do corpo, já que sobre ele silenciavam ou só tangenciavam, enquanto os estudos do pós-80, talvez por diversificarem os olhares, indicaram a consolidação desta "nova" história, transformando o corpo em "espaço constitutivo de laços sociais".

Eis uma idéia que, a meu ver, mereceria explicações a mais, se é que a compreendi bem. Estranha-me, à primeira vista, a hipótese de que os estudos sobre a sexualidade, mormente os empenhados em fazer a genealogia da repressão sexual, tenham silenciado sobre o corpo. Silenciavam sobre ele ou, pelo contrário, exageravam sua importância, ao pesquisar estratégias persecutórias ou pedagógicas que mais se preocupavam, na realidade, com as "coisas do espírito", tossem ligadas aos comportamentos ou mesmo à fé?

Estou de pleno acordo, por outro lado, com a afirmação de que os estudos sobre a sexualidade, em sua maioria, "evitaram uma reflexão crítica sobre o papel do corpo na história". Deixaram-se arrastar, muitas vezes, pelo que dizem os documentos, quando não caíram na armadilha denunciada por Foucault, colocando "o sexo em discurso" na ilusão de que o estavam explicando historicamente. 
"A história do corpo é hoje uma evidência", afirma Del Priore, solidamente ancorada em vasta bibliografia que, sem abrir mão das temáticas ligadas à sexualidade, diversificou as abordagens, conforme se vê no ensaio em questão. "Trabalhos, colóquios, livros - prossegue a autora - dão conta do interesse em explorar tal objeto". Mas seria mesmo um novo objeto? Um novo campo de investigação? Ou não passaria de um pretexto, quando muito uma temática para o estudo do poder, dos sentimentos, dos costumes?

Não posso negar que tenho dúvidas sobre a "novidade" teórica do "corpo como objeto" ao ler, em Jorge Crespo, a recomendação de que "a história do corpo deve ser perspectivada na longa duração e confrontada com a multiplicidade de tempos, espaços e técnicas elaboradas a partir de atitudes mentais que não é fácil delimitar" (Crespo 1990: 572). Bela definição - poder-se-ia dizer -, mas que já foi elaborada de várias maneiras a propósito da "velha" história das mentalidades. Nela não faltam a longa duração, o cruzamento dos tempos, as atitudes mentais e, por fim, o "tradicional" reconhecimento das dificuldades para delimitar tudo isso.

E também não posso evitar alguma inquietação ao ler, no mesmo Crespo, citado por Del Priore, que "a importância dada ao corpo, no nosso tempo, contrapõe-se ao ofuscamento a que estava submetido no passado" e que "o projeto de libertação do corpo está presente em cada momento, exprimindo-se numa dinâmica multifacetada e atingindo imensa teia de relações sociais" (1990: 7-16).

Quanto ao ofuscamento do corpo em nosso passado, eis uma idéia no mínimo discutível que não resistiria à prova empírica de vários tempos e sociedades. Quanto à "libertação do corpo", que estaríamos presenciando no mundo contemporâneo, e da qual a história do corpo seria uma espécie de porta-voz historiográfico, poderíamos contrapor o que Richard Sennett diz sobre o culto do corpo nas últimas décadas, relacionando-o ao egocentrismo narcisista, fisiolátrico no caso, hoje triunfante (1989: 27-22). Se assim for, estaríamos diante do "corpo cativo", e ao mesmo tempo tirano, não obstante a retórica da libertação do corpo encampada pela própria historiografia ałual. Mais uma armadilha em que caem os historiadores, conforme advertia, incansavelmente, Michel Foucault.

Mas não resta dúvida que Mary tem razão ao dizer que "hoje vivemos e pensamos as aventuras de nosso próprio corpo" e , também por isso (e muitol, a história do corpo é uma evidência eloqüente. Se é uma evidência historiográfica nova ou um dos vários refúgios das mentalidades, sempre tão atacadas desde o início, eis assunto para reflexão. Apenas um entre os vários e instigantes temas que este ensaio de fôlego propõe no presente Dossiê. 